\title{
Combined wind measurements by two different lidar instruments in the Arctic middle atmosphere
}

\author{
J. Hildebrand ${ }^{1}$, G. Baumgarten ${ }^{1}$, J. Fiedler ${ }^{1}$, U.-P. Hoppe ${ }^{2, *}$, B. Kaifler ${ }^{1}$, F.-J. Lübken ${ }^{1}$, and B. P. Williams ${ }^{3,{ }^{* *}}$ \\ ${ }^{1}$ Leibniz-Institute of Atmospheric Physics at the Rostock University, Kühlungsborn, Germany \\ ${ }^{2}$ University of Oslo, Department of Physics, Oslo, Norway \\ ${ }^{3}$ NorthWest Research Associates, Boulder, USA \\ * on leave from: Norwegian Defence Research Establishment (FFI), Oslo, Norway \\ ** now at: GATS, Inc., Boulder, USA \\ Correspondence to: J. Hildebrand (hildebrand@iap-kborn.de)
}

Received: 23 May 2012 - Published in Atmos. Meas. Tech. Discuss.: 12 June 2012

Revised: 5 September 2012 - Accepted: 23 September 2012 - Published: 19 October 2012

\begin{abstract}
During a joint campaign in January 2009, the Rayleigh/Mie/Raman (RMR) lidar and the sodium lidar at the ALOMAR Observatory $\left(69^{\circ} \mathrm{N}, 16^{\circ} \mathrm{E}\right)$ in Northern Norway were operated simultaneously for more than $40 \mathrm{~h}$, collecting data for wind measurements in the middle atmosphere from 30 up to $110 \mathrm{~km}$ altitude. As both lidars share the same receiving telescopes, the upper altitude range of the RMR lidar and the lower altitude range of the sodium lidar overlap in the altitude region of $\approx 80-85 \mathrm{~km}$. For this overlap region we are thus able to present the first simultaneous wind measurements derived from two different lidar instruments. The comparison of winds derived by RMR and sodium lidar is excellent for long integration times of $10 \mathrm{~h}$ as well as shorter ones of $1 \mathrm{~h}$. Combination of data from both lidars allows identifying wavy structures between 30 and $110 \mathrm{~km}$ altitude, whose amplitudes increase with height. We have also performed vertical wind measurements and measurements of the same horizontal wind component using two independent lasers and telescopes of the RMR lidar and show how to use this data to calibrate and validate the wind retrieval. For the latter configuration we found a good agreement of the results but also identified inhomogeneities in the horizontal wind at about $55 \mathrm{~km}$ altitude of up to $20 \mathrm{~ms}^{-1}$ for an integration time of nearly $4 \mathrm{~h}$. Such small-scale inhomogeneities in the horizontal wind field are an essential challenge when comparing data from different instruments.
\end{abstract}

\section{Introduction}

Wind and temperature measurements are fundamental for a comprehensive understanding of atmospheric dynamics. Radar instruments are capable of observing winds in the middle atmosphere up to $\approx 20 \mathrm{~km}$ and above $\approx 60 \mathrm{~km}$ altitude. Unfortunately, radar measurements are not possible in between, the so-called radar gap. The Rayleigh lidar technique covers this gap by performing temperature, wind, and aerosol soundings up to about $85 \mathrm{~km}$ altitude. Metal resonance lidars are able to derive temperature, wind speed and density of the accordant metal species at altitudes between 80 and $110 \mathrm{~km}$. Hence, the combination of different wind lidar techniques gives the possibility to derive continuous wind speed profiles in the entire altitude range up to $110 \mathrm{~km}$.

Lidars, which are able to measure winds in the middle atmosphere, are complex instruments. There are quite a few publications of wind measurements with sodium lidars between 85 and $105 \mathrm{~km}$ altitude (Liu et al., 2002; She et al., 2002; Williams et al., 2004) and only a few about wind measurements up to the stratopause using Rayleigh scattering (Tepley, 1994; Friedman et al., 1997; Souprayen et al., 1999; Huang et al., 2009; Xia et al., 2012). Even fewer observations are published about wind measurements covering the altitude range from the stratopause to the upper mesosphere (Baumgarten, 2010). In these publications the measured wind speeds are compared to winds derived by radiosondes, radars, or from models, with different results regarding the agreement of the methods. 
Two lidars that are capable of simultaneous temperature and wind measurements are located at the ALOMAR Observatory in Northern Norway $\left(69^{\circ} \mathrm{N}, 16^{\circ} \mathrm{E}\right)$ : the Rayleigh/Mie/Raman (RMR) lidar and the sodium (Na) resonance lidar. The ALOMAR research facility also hosts further instrumentation to study atmospheric dynamics. Continuous wind observations are available e.g. with the SKiYMET meteor radar in the altitude range of about 82 to $98 \mathrm{~km}$ (Singer et al., 2003) and with the MF radar in the altitude range of about 60 to $98 \mathrm{~km}$ (Singer et al., 1997). Sporadic measurement campaigns were conducted with meteorological rockets at the Andøya Rocket Range (e.g. Widdel, 1990; Müllemann and Lübken, 2005). A joint campaign of radar, lidar, and rocket instruments to derive waves in temperature and wind in the mesosphere conducted at Andøya Rocket Range in July 2002 is presented in Goldberg et al. (2006).

In this paper we show for the first time winds derived by two independent co-located lidars with the same line of sight in the altitude range from 30 up to $110 \mathrm{~km}$ altitude. The campaign was performed in January 2009. We also show how to validate the wind measurements of the RMR lidar without an external reference, using two independent lasers and telescopes of the system that can be tilted to opposite directions or a vertical pointed beam.

\section{Instruments}

The sounding volumes of the ALOMAR RMR lidar and the $\mathrm{Na}$ lidar are shown in Fig. 1. Both fields of view are slightly tilted against each other $(500 \mu \mathrm{rad})$. At $85 \mathrm{~km}$ altitude their diameters are $15 \mathrm{~m}$ (RMR lidar) and $48 \mathrm{~m}$ (Na lidar), respectively. Shown are also the sounding volumes of the colocated SKiYMET meteor radar and the MF radar. Their fields of view are $90^{\circ}$ (SKiYMET) and $60^{\circ}(\mathrm{MF}$ ), yielding diameters at $85 \mathrm{~km}$ altitude of $170 \mathrm{~km}$ and $98 \mathrm{~km}$, respectively. The lidars measure at a distinct point in the sky, whereas the radars cover a very large part of the sky. This is comparable to a spatial smoothing. Due to this fundamental difference in technique already noted by Liu et al. (2002), we do not include data obtained by the radars to avoid difficulties when comparing lidar measurements with radar measurements due to different sizes of sounding volumes.

\subsection{ALOMAR RMR lidar}

The ALOMAR RMR lidar has been routinely measuring temperatures and aerosols since 1997 (von Zahn et al., 2000). During the last years it was upgraded to measure wind speeds as well. The Doppler Rayleigh Iodine Spectrometer (DoRIS) relies on the Doppler shift of light backscattered by moving air molecules. Since the relative Doppler shift of the laser light with frequency $f$ is of the order of $\frac{\Delta f}{f} \approx 10^{-8}$ only, special care about the stability of the emitter and the detection

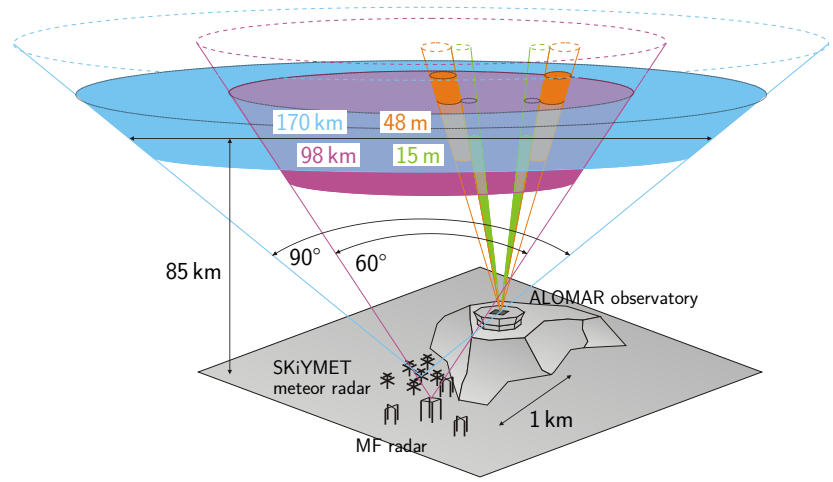

Fig. 1. Sounding volumes of RMR lidar (green), Na lidar (orange), meteor radar (blue), and MF radar (purple). The filled parts of the cones indicate the actual sounding volumes. The colored numbers indicate diameters of the corresponding sounding volumes at $85 \mathrm{~km}$ altitude.

system is needed. A detailed description and first results are presented in Baumgarten (2010).

The ALOMAR RMR lidar employs two identical power lasers with a peak power of $50 \mathrm{MW}$ (mean power $14 \mathrm{~W}$ ) at a wavelength of $532 \mathrm{~nm}$ (which is used for DoRIS) and a repetition rate of $30 \mathrm{~Hz}$ each. Ultraviolet $(355 \mathrm{~nm})$ and infrared $(1064 \mathrm{~nm})$ light are also emitted but not used for wind measurements. Both transmitting lasers are injection-seeded by one single seed laser, whose frequency is stabilized by iodine absorption spectroscopy at line $1109(\lambda=532.260 \mathrm{~nm})$ (Baumgarten, 2010). This frequency stability was found to be better than $6 \mathrm{MHz}$ over three years, and for an exemplary day in January 2009 we found $200 \mathrm{kHz}$ over $24 \mathrm{~h}$. Nevertheless, there might be some frequency offset between power lasers and seed laser. This offset is monitored on single pulse basis for both lasers using an $\mathrm{I}_{2}$ pulse spectrometer (Fiedler et al., 2008) and taken into account in the wind retrieval. We found a typical offset of $10-20 \mathrm{MHz}$, depending on the laser, for the period of January 2009. A frequency offset of $1 \mathrm{MHz}$ corresponds to a wind speed offset of $0.266 \mathrm{~ms}^{-1}$. The outgoing pulsed laser beams are expanded to a diameter of $20 \mathrm{~cm}$ (beam divergence $70 \mu \mathrm{rad}$ ) and emitted along the optical axis of the receiving telescopes. Both telescopes are independently tiltable from zenith pointing up to $30^{\circ}$ off-zenith. The telescopes are called North-West Telescope (NWT) and South-East Telescope (SET) since they can be steered to the north-west quadrant and to the south-east quadrant, respectively. Their primary mirrors have a diameter of $1.8 \mathrm{~m}$. The field of view (FOV) is $180 \mu \mathrm{rad}$. Light received by both telescopes is alternately coupled into one single polychromatic detection system using a segmented rotating mirror (rotary fiber selector, RFS). A sketch of the DoRIS branch of the detection system is shown in Fig. 2. The light from the SET is reflected at the mirror of the RFS, while the light from the NWT passes through a hole in the mirror. DoRIS uses only the backscattered light of the $532 \mathrm{~nm}$ emission, which 


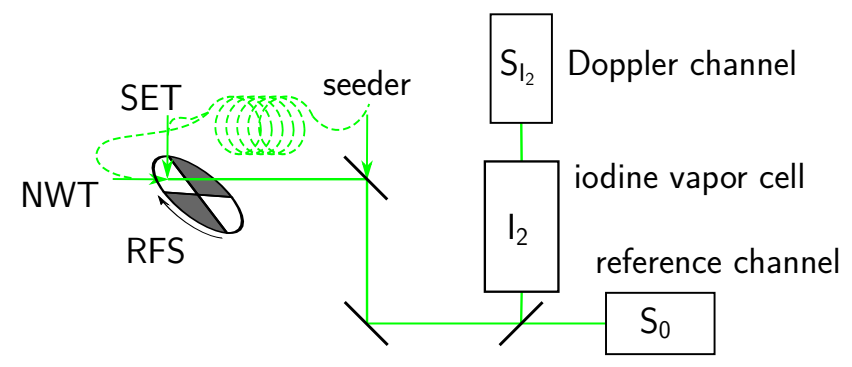

Fig. 2. Sketch of the DoRIS branch of the detection system. During operation backscattered light from both telescopes (NWT, SET) is alternately coupled into the detection system using a rotary fiber selector (RFS); light from the stabilized seed laser enters through an additional entrance (solid line) after the RFS. Reference channel $\left(S_{0}\right)$ and Doppler channel $\left(S_{\mathrm{I}_{2}}\right)$ consist each of three intensity cascaded detectors. For calibration measurements light from the seed laser can additionally be coupled into the detection system through the telescope entrances (dashed fibers).

is split into two beams. One beam is detected directly, the so-called reference channel. The other one passes through an iodine-vapor cell, the so-called Doppler channel. The transmittance of the iodine-vapor cell depends strongly on wavelength, hence on Doppler shift. The cell is heated to constant temperature of $38^{\circ} \mathrm{C}$ to ensure that all $\mathrm{I}_{2}$ is in the gas phase (Baumgarten, 2010). The signal of the reference channel $\left(S_{0}\right)$ does not depend on wind speed, but the signal of the Doppler channel $\left(S_{\mathrm{I}_{2}}\right)$ does. To remove the effect of transmission through the atmosphere, we calculate the ratio of both signals, which we call Doppler ratio $D=S_{\mathrm{I}_{2}} \cdot S_{0}^{-1}$. Each channel is actually a group of three detectors. They build an intensity cascade to increase the dynamic range of the detection system and hence the altitude range of the measurement.

The quantum efficiencies of the detectors might vary with time (e.g. due to temperature variations). To monitor such variations during lidar operation, light from the stabilized seed laser is coupled into the optical bench $1 \mathrm{~ms}$ after each laser pulse. This yields the seeder (Doppler) ratio $D_{\text {seeder }}$, which describes the behavior of the detection channels. The light from the seed laser enters the optical bench through a different entrance than the backscattered light from the telescopes (see Fig. 2). However, the Doppler ratio $D$ depends on the way the light is coupled into the detection system, namely through seeder or telescope entrance (Baumgarten, 2010). These differences are caused by different images of the entrances on the detector areas. During calibration measurements it is possible to feed light from the seed laser additionally through both telescope entrances simultaneously (dashed fiber in Fig. 2). Thus it is possible to determine the entrance ratio $E_{\text {telescope }}=D_{\text {telescope }} \cdot D_{\text {seeder }}^{-1}$, which relates the Doppler ratios measured using either telescope entrance $\left(D_{\text {telescope }}\right)$ or seeder entrance $\left(D_{\text {seeder }}\right)$. This system parameter is usually constant in time, and varies only when the design of the optical bench or the telescope fibers is

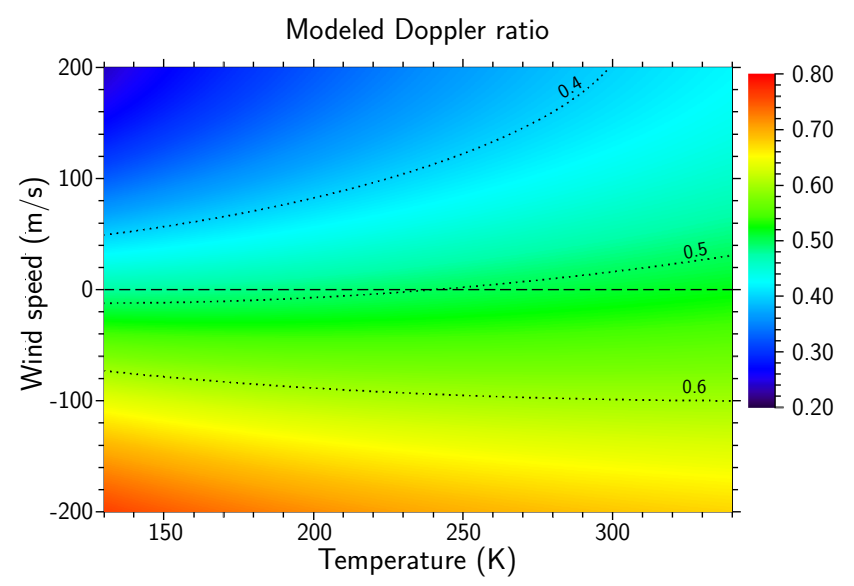

Fig. 3. Modeled matrix of Doppler ratio as function of temperature and wind speed; dotted lines are isolines for 0.4, 0.5, and 0.6; dashed line indicates zero wind speed. The Doppler ratio is more sensitive to wind speed than to temperature and not a symmetric function of wind speed.

changed. We found $E_{\mathrm{NWT}}=0.9917$ and $E_{\mathrm{SET}}=0.8776$ (measured in February 2009); differences between NWT and SET are caused by the fact that light from the SET is reflected at the mirror of the RFS, while the light from the NWT passes through a hole in the RFS. This calibration is performed without any external data; hence we call it "internal calibration". Finally, when seeder ratio $D_{\text {seeder }}$ and entrance ratio $E_{\text {telescope }}$ are taken into account, the actual Doppler ratio $D^{\prime}$ results from the measured Doppler ratio $D$ according to $D^{\prime}=D \cdot D_{\text {seeder }}^{-1} \cdot E_{\text {telescope }}$.

The reference channel allows us to measure relative densities simultaneously to wind measurements. Atmospheric temperature is derived using hydrostatic integration of measured relative densities (Kent and Wright, 1970; Hauchecorne and Chanin, 1980). When temperature is known, the Doppler ratio is a unique measure of line-ofsight wind speed. The retrieval of wind speed from measured Doppler ratio and temperature uses a modeled lookup table of Doppler ratio as function of wind speed and temperature. This is shown in Fig. 3. The shape of the modeled Doppler ratio matrix is determined by the shape of the absorption line of the iodine-vapor cell. It is apparent that the wind speed response is much steeper than the temperature dependence: $\frac{\partial D}{\partial v}=10^{-3} \mathrm{~ms}^{-1}$ and $\frac{\partial D}{\partial T}=1.8 \times 10^{-4} \mathrm{~K}^{-1}$, for $v=0 \mathrm{~ms}^{-1}$ and $T=230 \mathrm{~K}$.

\subsection{Na lidar}

The Na lidar at ALOMAR measures sodium densities, temperatures, and winds in the sodium layer at about $80-110 \mathrm{~km}$ altitude (She et al., 2002; Williams et al., 2004; Kaifler, 2009). The measurement principle relies on resonance fluorescence at the $\mathrm{D}_{2}$ line of sodium at $589.16 \mathrm{~nm}$. The $\mathrm{D}_{2}$ line is alternately probed with three frequencies, separated by 
$630 \mathrm{MHz}$. Atmospheric temperature is determined by measuring the width of the Doppler broadening of the $\mathrm{D}_{2}$ line due to thermal motion. Atmospheric motion causes a frequency shift of the $\mathrm{D}_{2}$ line. This frequency shift is measured by comparing the normalized backscatter signal at three different points of the $\mathrm{D}_{2}$ line, which are separated by $630 \mathrm{MHz}$ (Kaifler, 2009).

The Na lidar employs one transmitting laser with a mean power of $350 \mathrm{~mW}$ and a repetition rate of $50 \mathrm{~Hz}$.

Seed light for the pulsed dye amplifier is generated by sum frequency generation. The beams of two diode-pumped Nd:YAG lasers, 1319 and $1064 \mathrm{~nm}$, are combined and pass through a periodically poled lithium niobate (PPLN) crystal (Yue et al., 2009). In order to increase long-term stability, the seed laser is locked to the $\mathrm{Na}_{2}$ line using Doppler-free spectroscopy. This introduces a frequency dither of $2.9 \mathrm{MHz}$, which, however, averages to approximately zero over the integration time used in the wind retrieval. Frequency stability of the output at $589 \mathrm{~nm}$ is better than $0.6 \mathrm{MHz}$ over $2 \mathrm{~min}$ as measured with a Fabry-Pérot interferometer. This FabryPérot interferometer is a temperature-stabilized air-spaced etalon with $1 \mathrm{GHz}$ free spectral range, $800 \mathrm{~mm}$ diameter, and $45 \mathrm{~mm}$ working aperture; the finesse is about 20 (Kaifler, 2009).

After expansion (divergence $450 \mu \mathrm{rad}$ ) the beam is split into two beams, which are directed to beam steering units. These are mounted about $3 \mathrm{~m}$ off the telescope axis. The $\mathrm{Na}$ and the RMR lidar use the same receiving telescopes. The focal optics of the Na lidar yield a FOV of $600 \mu \mathrm{rad}$ which is tilted against the FOV of the RMR lidar to avoid crosstalk/interference by $500 \mu \mathrm{rad}$ (see Fig. 1).

At the altitude where the height ranges of both lidars overlap (roughly $80-85 \mathrm{~km}$ ), the fields of view have diameters of about $15 \mathrm{~m}$ and $48 \mathrm{~m}$ for RMR and Na lidar, respectively. Since they are slightly tilted against each other, their centers are separated by $40 \mathrm{~m}$. These distances are covered by air motion in a few seconds, which is much shorter than the integration times of both lidars. Typical wind speeds in the altitude range of the overlap of both lidars are greater than $10 \mathrm{~ms}^{-1}$. For this reason it is appropriate to state that both lidars sound in a common volume. The fact that the $\mathrm{Na}$ lidar is tilted by $500 \mu \mathrm{rad}$ against the actual viewing direction of the telescopes leads to an error of the derived wind speeds due to the projection of less than $\frac{\Delta v}{v}<2 \times 10^{-4}$.

\section{Database and analysis}

The RMR lidar records backscattered light with an internal integration of 1000 laser pulses $(\approx 33 \mathrm{~s})$, sorted to range bins of $50 \mathrm{~m}$. For this study the data were gridded to records with a length of $5 \mathrm{~min}$ and height bins of $150 \mathrm{~m}$. Since the wind retrieval is not applicable for an aerosol loaded atmosphere yet, we limit our measurements to altitudes above $30 \mathrm{~km}$, i.e. above the stratospheric aerosol layer (Junge et al., 1961).
The top altitude is determined as the altitude where the error of the backscatter signal due to photon noise plus uncertainty in determining the background signal exceeds half the signal. We discard an individual record if its top altitude is more than $5 \mathrm{~km}$ lower than the ninth decile of all top altitudes throughout the observation. This might cause few gaps due to thin tropospheric clouds but enhances the overall data quality. To simplify further retrieval we build a composite signal for each channel by combining the signal of the three cascaded detectors. For this the signal of the next lower detector is normalized to the signal of the higher detector, the normalization factor is determined in an altitude range of $7 \mathrm{~km}$ where the signals of both detectors overlap. Subsequently, the backscatter signal is smoothed in altitude with a running mean filter using a window size of $3 \mathrm{~km}$. The time smoothing (running mean filter with window size of $1 \mathrm{~h}$ ) is applied on calculated temperature and Doppler ratio data, respectively. Finally, we take the resulting wind speed values into account only for wind speed errors less than $20 \mathrm{~ms}^{-1}$. The wind speed error is derived by performing error propagation during all calculations, starting with measurement uncertainties for all measured quantities, e.g. backscatter signal or frequency offset of power lasers.

The data acquisition of the Na lidar stores raw data files, which contain data of $15 \mathrm{~s}$, meaning 250 laser pulses for each of the three frequencies. The length of a range bin is $150 \mathrm{~m}$. For each frequency the fluorescence signal is normalized to the Rayleigh signal between 35 and about $45 \mathrm{~km}$ altitude to account for differences in emitted laser power and tropospheric transmission. To match data acquired by the RMR lidar, the retrieved wind speeds were smoothed $(1 \mathrm{~h}, 1 \mathrm{~km})$ and gridded to records of five minutes and height bins of $150 \mathrm{~m}$.

In January 2009 the RMR lidar and Na lidar were operated for more than $40 \mathrm{~h}$ simultaneously. The data presented here (see Table 1) include two long observations of $11.5 \mathrm{~h}$ and $10 \mathrm{~h}$, one of about $5.5 \mathrm{~h}$, and some shorter ones. During five observations the South-East Telescope pointed to zenith, measuring vertical wind. This allows us to validate the wind measured with the SET, since the mean vertical wind is expected to be close to zero when averaging over an extensive altitude range $(>10 \mathrm{~km})$ and long integration times $(>1 \mathrm{~h})$ (Hoppe and Fritts, 1995). A possibility to validate retrieved wind speeds without external or atmospheric reference is to compare winds measured with both telescopes pointing in opposite viewing directions (same viewing direction would be even better but is not possible due to the construction of the observatory). The telescopes were pointed in opposite directions during two measurements: west-east (zonal) wind was derived simultaneously by NWT pointing to west and SET pointing to east. For comparison of absolute wind speeds derived independently by RMR and Na lidar, we use data obtained during the three longest observations. 
Table 1. Joint observations of RMR lidar and Na lidar in January 2009. Only observations presented in this paper are listed.

\begin{tabular}{|c|c|c|c|c|c|c|c|}
\hline \multirow{2}{*}{$\begin{array}{l}\text { Day of } \\
\text { January } 2009\end{array}$} & \multicolumn{2}{|c|}{ Start } & \multicolumn{2}{|c|}{ Stop } & \multicolumn{2}{|c|}{ Direction } & \multirow[t]{2}{*}{ Application } \\
\hline & RMR & $\mathrm{Na}$ & RMR & $\mathrm{Na}$ & NWT & SET & \\
\hline 17 & $15: 45$ & $15: 45$ & $20: 45$ & $20: 45$ & meridional & vertical & atmospheric calibration \\
\hline \multirow[t]{2}{*}{19} & $17: 10$ & $15: 40$ & $18: 35$ & $18: 30$ & meridional & vertical & atmospheric calibration \\
\hline & 20:00 & 20:00 & $22: 10$ & $22: 10$ & meridional & vertical & atmospheric calibration \\
\hline \multirow[t]{2}{*}{$22 / 23$} & $17: 35$ & $18: 55$ & $02: 30$ & $02: 30$ & meridional & vertical & RMR vs. Na comparison \\
\hline & $02: 40$ & 03:45 & $07: 15$ & $07: 15$ & meridional & zonal & RMR vs. Na comparison \\
\hline $23 / 24$ & $22: 10$ & $16: 30$ & 01:00 & 01:00 & meridional & vertical & atmospheric calibration \\
\hline \multirow[t]{2}{*}{25} & $01: 50$ & $00: 55$ & $03: 15$ & $03: 15$ & zonal & vertical & atmospheric calibration \\
\hline & $03: 25$ & 03:20 & $07: 15$ & $07: 45$ & zonal & zonal & RMR vs. RMR, RMR vs. Na \\
\hline $26 / 27$ & $16: 35$ & $15: 20$ & 03:00 & $07: 50$ & zonal & zonal & RMR vs. Na comparison \\
\hline
\end{tabular}

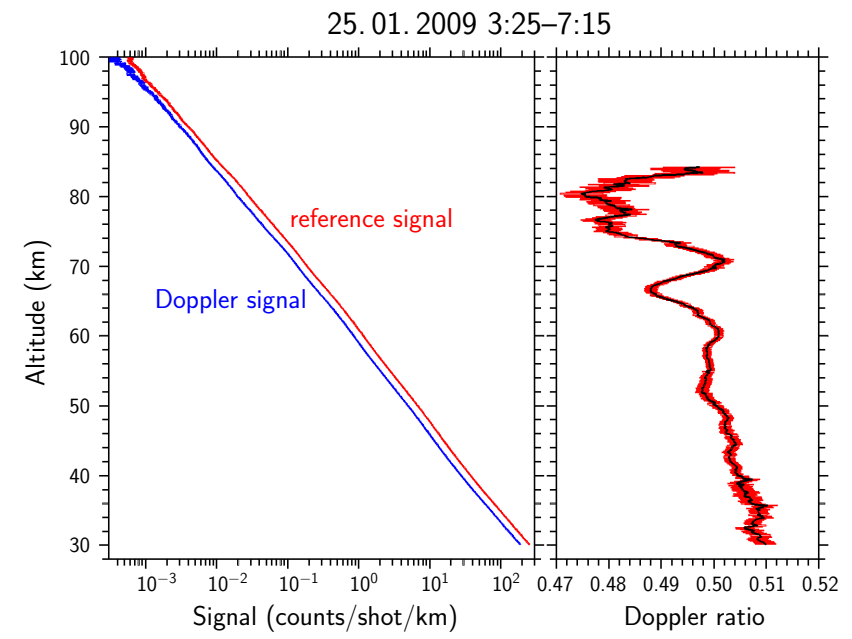

Fig. 4. Left panel: vertical profiles of the backscatter signal (NWT) on 25 January 2009. The red profile shows the reference signal measured in front of the iodine-vapor cell. The blue profile shows the Doppler signal measured behind the iodine cell, which depends on wind speed. Right panel: ratio of both signals (Doppler ratio $D^{\prime}$ ); red horizontal bars indicate measurement uncertainty.

\section{Results}

The next three sections address the wind retrieval of the RMR lidar and two methods of atmospheric validation and calibration of the RMR lidar. Afterwards combined results from joint measurements of RMR lidar and $\mathrm{Na}$ lidar are shown.

\subsection{Raw signals and Doppler ratio}

To show an example of the retrieval method from the raw signals to the derived winds, we have selected the measurement on 25 January as the telescopes were tilted in opposite directions on that day.

The left panel of Fig. 4 shows vertical backscatter profiles obtained during the measurement on 25 January, between 03:25 and 07:15 UT with the NWT. The profile with the higher count rate was detected by the channel before the iodine cell, meaning the reference signal. The other one was detected behind the iodine cell, yielding the Doppler signal. Both profiles are already composites of three detectors. The ratio of both signals is the Doppler ratio $D^{\prime}$, shown in the right panel of Fig. 4, which is mainly determined by wind speed and slightly influenced by temperature.

During this measurement the NWT pointed to west, measuring zonal wind speed. The SET was steered to east, probing zonal wind speed as well. In Fig. 5 we compare the height profiles of Doppler ratios obtained with NWT and SET measuring both the same horizontal wind component in opposite directions (hence line-of-sight wind has opposite sign). On first view both profiles look like mirrored (as expected), which is most obvious in the upper part. The mirror axis is approximately a line connecting the intersections of both profiles (not shown). The black line is a Doppler ratio profile calculated with regard to measured atmospheric temperature for zero wind speed. The fact that this line is not straight but curvy results from dependence of the Doppler ratio on atmospheric temperature. This line is not exactly the mirror axis of both measured Doppler ratio profiles due to two reasons: First, both measured wind speeds are not exactly the same, e.g. there is an inhomogeneity in the wind field between 50 and $60 \mathrm{~km}$ altitude (see Sect. 4.2). Second, one telescope measures positive line-of-sight wind while the other one measures negative line-of-sight wind; since Doppler ratio is not a symmetric function of wind speed (see isolines in Fig. 3), this results in different offsets of the actual Doppler ratios against the Doppler ratio for zero wind speed.

\subsection{Zonal wind measured with independent telescopes of the RMR lidar}

In this section we show that indeed vertical profiles of zonal wind speed measured by both telescopes match very well in a large part of the probed height range. This corresponds to the "mirrored" behavior presented in the previous section. The upper panels of Fig. 6 show the zonal wind speed (panel a) and temperature (panel b) derived from data shown 


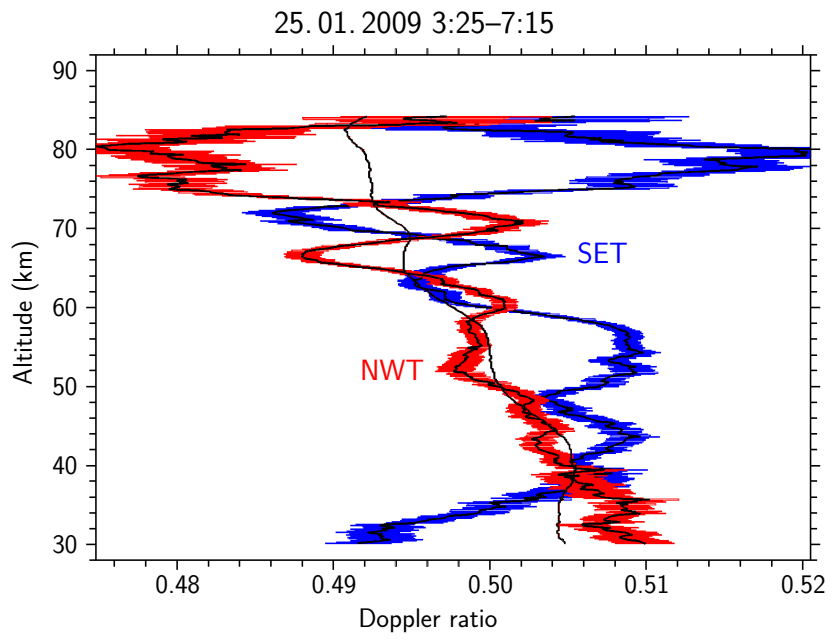

Fig. 5. Mean profiles of Doppler ratio for the NWT (red error bars) and the SET (blue error bars), both measuring zonal wind speed, but in opposite directions. The black line shows the calculated Doppler ratio for zero wind speed with regard to measured atmospheric temperature.

in Fig. 4. In the wind speed plot a profile of ECMWF wind data is included for comparison. The European Center for Medium-Range Weather Forecasts (ECMWF) provides an operational forecast model (Integrated Forecast System, IFS) which assimilates real data. We use IFS version Cy35r1, T799, extracted for $69.28^{\circ} \mathrm{N}, 16.01^{\circ} \mathrm{E}$. On first view the comparison between both systems of the RMR lidar is quite good, with some limitations. The ECMWF profile shows some deviations to the measured wind profiles (e.g. $\approx 20 \mathrm{~ms}^{-1}$ around $45 \mathrm{~km}$ altitude and $\approx 30 \mathrm{~ms}^{-1}$ around $72 \mathrm{~km})$. However, we do not observe a systematic over- or underestimation of winds in the ECMWF data. The differences arise due to the wavy structure in ECMWF and observations, which are not in phase.

At first attempt the SET wind speed on that day matched neither the NWT data nor the ECMWF data. We identified a technical problem leading to a change in the entrance ratio $E_{\mathrm{SET}}$ (see Sect. 4.3). Thus, we discarded $E_{\mathrm{SET}}$ obtained from the internal calibration measurement and instead used the value derived from a measurement of vertical wind speed earlier that morning (see Sect. 4.3 for details).

The wind speed profiles (see Fig. 6a) match very well above $60 \mathrm{~km}$ altitude and between 35 and $50 \mathrm{~km}$, but differ in the altitude range between 50 and $60 \mathrm{~km}$, and below $35 \mathrm{~km}$ altitude by about $+20 \mathrm{~ms}^{-1}$ and $-25 \mathrm{~ms}^{-1}$, respectively. The comparison of the temperature profiles (see Fig. 6b) shows a similar behavior. They match very well between 58 and $72 \mathrm{~km}$ and between 40 and $50 \mathrm{~km}$ altitude, but differ in the upper part above $72 \mathrm{~km}$ (where the signal quality becomes worse), around $55 \mathrm{~km}$ altitude (where we also find the differences in wind speed), and below $40 \mathrm{~km}$.
Since the sounding volumes of both lidar beams are separated by $\approx 40 \mathrm{~km}$ at $55 \mathrm{~km}$ altitude, the differences in wind speed and temperature at this altitude might be caused by an inhomogeneous wind and temperature field. At $30 \mathrm{~km}$ altitude we do not expect the relatively large differences of $25 \mathrm{~ms}^{-1}$ and $4 \mathrm{~K}$, respectively, to be caused by horizontal inhomogeneities since the lidar beams are separated by only $22 \mathrm{~km}$ at this altitude. Furthermore, if we assume that the differences were caused by freely propagating gravity waves, the amplitude increases with altitude with a scale height of about $14 \mathrm{~km}$, resulting in unrealistic amplitudes at altitudes of $60 \mathrm{~km}$ and above. Hence, the differences below $40 \mathrm{~km}$ are probably due to a technical reason caused by an unstable phase of the rotary fiber selector, which would result in a height-dependent backscatter signal for reference channel and Doppler channel. Addressing the observed differences in the altitude range of 50 to $60 \mathrm{~km}$, we can rule out a technical reason for this spatially limited wind difference: a misbehavior of the instrument cannot cause effects confined to such a limited altitude range.

Moreover, we can rule out that the differences in wind speed are caused by faulty treatment of the temperature effect in the wind retrieval as the temperature differences between NWT and SET are only $2 \mathrm{~K}$. Even when neglecting this temperature difference, the wind speed would be off by no more than $0.4 \mathrm{~ms}^{-1}$ line-of-sight wind, which is about $10 \%$ of the error bars. So the response of the Doppler ratio on temperature is too weak that such a small error in temperature would cause the observed deviation in wind speed.

We now investigate the question of if the differences between NWT and SET data are due to wave-induced perturbations. For that we use the following procedure for processing wind and temperature data. At first we approximate the undisturbed background profile by fitting a polynomial of fourth degree to the measured data. We tested various polynomials of different orders and found fourth order to be the best representation of the undisturbed background profile (Cot and Barat, 1986 used a similar order for estimation of background wind profiles in a case study of wave-turbulence interaction in the stratosphere). Then we calculate a residual profile by subtracting the background profile from the actually measured profile. Finally, we determine the difference between NWT and SET residuals. The resulting vertical profiles are shown in the lower panels of Fig. 6. The profile of wind speed difference (panel c) shows a wavelike structure with highest significant amplitude of about $10 \mathrm{~ms}^{-1}$ at $55 \mathrm{~km}$ altitude. At this altitude the temperature difference (panel d) is about $0.5 \mathrm{~K}$, while it is almost zero in the remaining altitude range. Thus, wind speed and temperature differences show the highest amplitude at the same altitude. This indicates that the differences between NWT and SET wind and temperature data between 50 and $60 \mathrm{~km}$ altitude are caused by atmospheric gravity waves. Since the horizontal distance of the sounding volumes is about $40 \mathrm{~km}$, the horizontal wavelength of a wave has to be much shorter or much longer 
25. $01.20093: 25-7: 15$
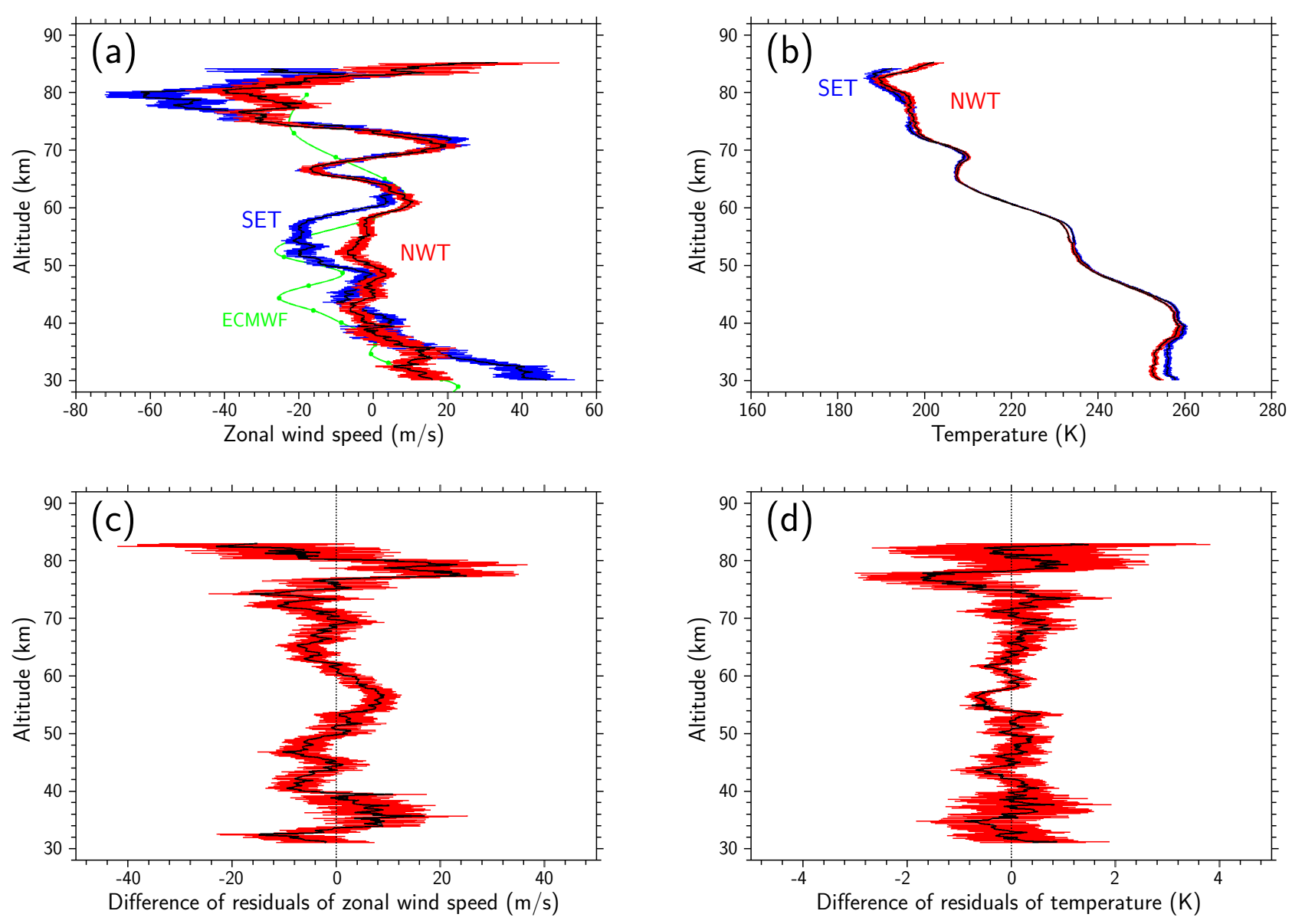

Fig. 6. Vertical profiles of zonal wind speed and temperature on 25 January between 03:25 UT and 07:15 UT obtained by NWT (red error bars) and SET (blue error bars) and the difference of their respective residuals. (a) Zonal wind speed: green line shows ECMWF data for 06:00 UT (dots mark the model levels). (b) Temperature. (c) Wind difference between NWT and SET after subtracting a polynomial fitted background wind profile (see text for details). (d) Same as panel (c) but for temperature.

than $40 \mathrm{~km}$. For details of such waves see e.g. Alexander and Barnet (2007).

\subsection{Vertical wind measurements}

As mentioned in Sect. 4.2 the entrance ratio may vary slightly for the South-East Telescope due to the way the light from SET is coupled into the detection system. Light from SET is reflected at the RFS into the detection system (see Fig. 2), and a misalignment between the mirror surface and the plane of rotation of the RFS can cause angular deviations of the beam towards the detectors. These are converted by the long optical path $(\approx 4 \mathrm{~m})$ in combination with the small detector area $\left(\approx 0.024 \mathrm{~mm}^{2}\right)$ into beam displacements at the detectors that cause small signal variations. This results in a dependence of $E_{\mathrm{SET}}$ on the phase of the RFS relative to the laser pulse (i.e. the place of reflection on the RFS). These changes of $E_{\mathrm{SET}}$ would in turn lead to inaccurate wind speeds. Wind speeds derived with the NWT are not affected, since the backscattered light passes the RFS through a hole. Since vertical wind is expected to be close to zero for long integration times (see discussion above), vertical wind measurements allow us to identify calibration problems. Therefore, we use the zenith measurements performed with the SET (see Table 1) to validate or, if needed, to correct the entrance ratio obtained during calibration. For this we vary $E_{\mathrm{SET}}$ until we obtain a mean vertical wind speed close to zero in the altitude range between 50 and $60 \mathrm{~km}$, where data quality is best (lower part of the most sensitive detector). We scanned the data carefully for wave patterns in the vertical winds like those we show in Sects. 4.4 and 4.6 for horizontal winds but did not observe any similar structures. Table 2 lists results from zenith measurements during the campaign. For example, on 17 January applying the entrance ratio derived from the internal calibration yields a mean vertical wind speed of $-1.7 \mathrm{~ms}^{-1}$, or, when corrected to give zero vertical wind, the entrance ratio 

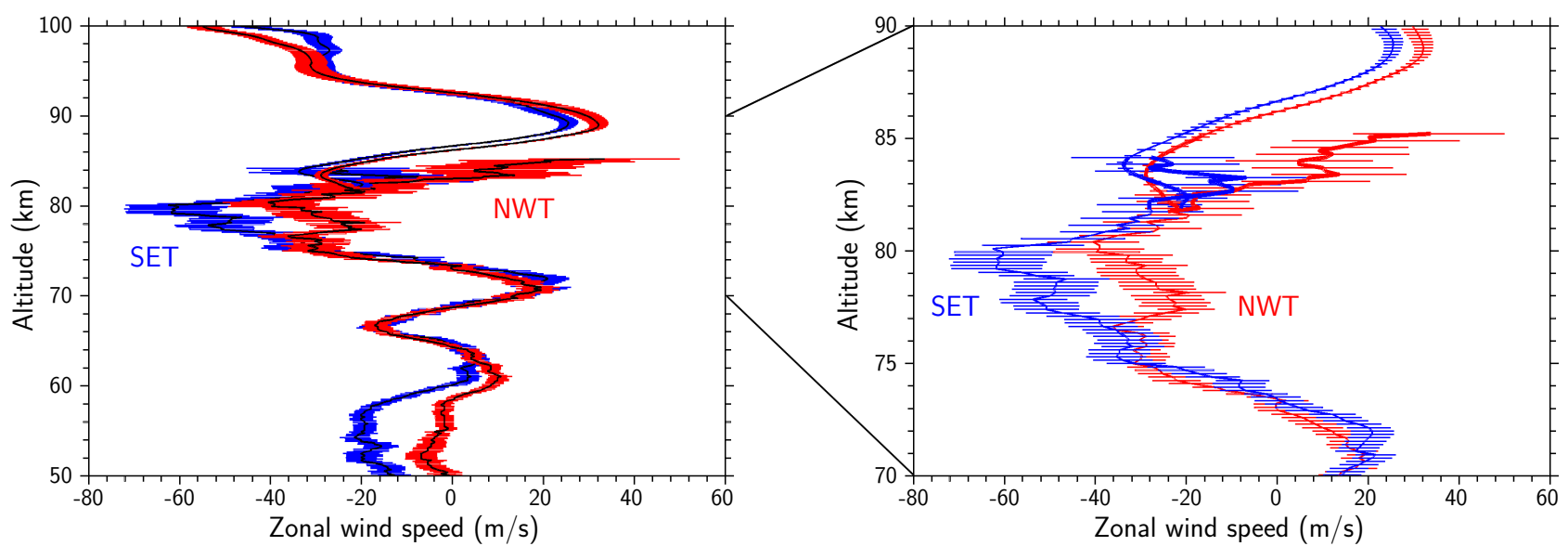

Fig. 7. Zonal wind measured by RMR lidar and Na lidar on 25 January, averaged between 03:25 UT and 07:15 UT. The NWT (red) pointed to west, the SET (blue) to east. In the altitude range of overlap $(\approx 82-85 \mathrm{~km})$, wind speed profiles from both lidar systems are shown. Left panel: altitude range between 50 and $100 \mathrm{~km}$. Right panel: close-up between 70 and $90 \mathrm{~km}$ altitude; between 80 and $85 \mathrm{~km}$ error bars are shown for each other data point only; thick lines highlight the height range of overlap.

Table 2. Vertical pointing measurements with SET. Second column shows the apparent vertical wind speed between 50 and $60 \mathrm{~km}$ altitude derived by internal calibration $\left(E_{\mathrm{SET}}=0.8776\right)$. Third column shows resulting $E_{\mathrm{SET}}$ as calculated for zero vertical wind speed (atmospheric calibration).

\begin{tabular}{lccr}
\hline Date & $\Delta w / \mathrm{ms}^{-1}$ & $E_{\text {SET }}$ & duration/h \\
\hline 17 January & -1.7 & 0.8750 & 4.5 \\
19 January & -7.1 & 0.8649 & 3.5 \\
22/23 January & -5.7 & 0.8676 & 9 \\
23/24 January & -7.2 & 0.8647 & 2.75 \\
25 January & -8.9 & 0.8611 & 1.33 \\
\hline
\end{tabular}

has to be lowered to $0.8750(-0.3 \%)$. On 25 January the initially derived mean vertical wind speed was $-8.9 \mathrm{~ms}^{-1}$; using an entrance ratio of $0.8611(-1.9 \%)$ results in zero vertical wind.

This is the first time that it is possible to monitor the stability of the detection system and to take system instabilities into account for further retrieval. We call this method "atmospheric calibration". For measurements of horizontal wind with the SET, this atmospheric calibration is available only for 25 January (see Table 1). For all other observations we show data from the NWT only to avoid uncertainties due to insufficient calibration of SET data. It should be noted that the instability was traced to mechanical and electronic problems of the RFS that were solved recently.

\subsection{Combination of RMR and Na data}

In this section we expand the height range for wind measurements by including data obtained by the $\mathrm{Na}$ lidar at
ALOMAR. During the morning of 25 January, the Na lidar was in operation providing zonal wind speed in the altitude range from about 80 to $100 \mathrm{~km}$. Figure 7 shows the same RMR lidar data as in Fig. 6 and includes also zonal wind speed measured with the Na lidar. The left panel shows the altitude range between 50 and $100 \mathrm{~km}$; the right panel shows a close-up between 70 and $90 \mathrm{~km}$ to emphasize the overlap of RMR and Na lidar. Between 82 and $85 \mathrm{~km}$ altitude, the wind speed data are available from both instruments. At the lower limit of the $\mathrm{Na}$ data ( $82 \mathrm{~km}$ altitude), the wind speed profiles of RMR and Na lidar intersect. Above that altitude the wind profiles derived by RMR lidar and $\mathrm{Na}$ lidar differ for the NWT, whereas for the SET the comparison of RMR and Na lidar data is better: within the error bars both profiles show the same wind speed in nearly the whole altitude range of overlap (RMR: $(-19.9 \pm 14.2) \mathrm{ms}^{-1}$, Na: $\left.(-26.6 \pm 1.8) \mathrm{ms}^{-1}\right)$.

It should be noted that these wind speeds were derived independently by two completely different instruments, and the altitude range of overlap is at the limit of the signal range for both lidars.

For further study we build a composite vertical profile of zonal wind speed (left panel of Fig. 8): below $82 \mathrm{~km}$ altitude we use the RMR data and above $82 \mathrm{~km}$ the $\mathrm{Na}$ data, which have much smaller errors bars than the RMR data $\left(<5 \mathrm{~ms}^{-1}\right.$ vs. $15-20 \mathrm{~ms}^{-1}$ ). Since the respective wind speed profiles intersect at that altitude, there is no discontinuity. The profiles indicate some wave structure, whose amplitude varies with height. To highlight this wavelike structure, we calculate the residual wind speed profile after subtracting the background wind. We compute a polynomial of fourth degree to approximate the background wind (similar to the procedure in Sect. 4.2). This is shown in the left panel of Fig. 8. The 


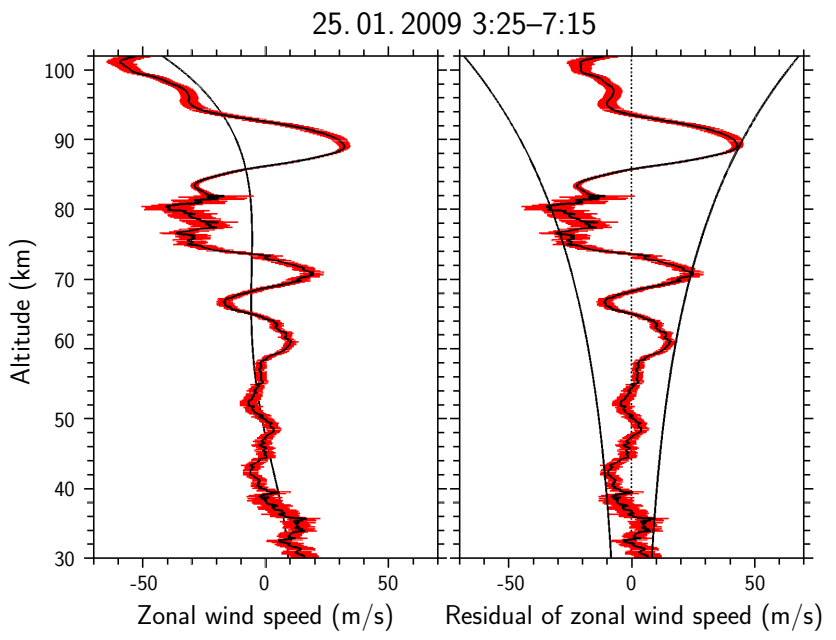

Fig. 8. Left panel: combined vertical profile of zonal wind speed measured with the NWT; below $82 \mathrm{~km}$ altitude RMR lidar data are shown, above $82 \mathrm{~km} \mathrm{Na}$ lidar data; the black line shows a polynomial fit of fourth degree representing the estimated background wind speed. Right panel: residual between measured wind speed and estimated background highlights perturbations in the vertical wind profile; the black lines show an envelope indicating the exponential increase of the perturbation amplitude.

right panel shows the residual between measured wind speed and approximated background wind. We observe that the amplitude increases with height: at $(40 / 60 / 80) \mathrm{km}$ altitude the amplitude is about $(10 / 15 / 35) \mathrm{ms}^{-1}$. This behavior is typical for upward propagating gravity waves (Fritts and Alexander, 2003) where the amplitude scale height is about $H_{\hat{u}} \approx 2 H_{p}$ ( $H_{p}$ is the pressure scale height of $\approx 7 \mathrm{~km}$ ).

We fitted an envelope to the data in the form $\hat{u}=a+$ $\exp \left((z+b) / H_{\hat{u}}\right)$ (black lines), and deduced the parameters $a=3.6 \mathrm{~ms}^{-1}, b=12.2 \mathrm{~km}$, and $H_{\hat{u}}=27.4 \mathrm{~km}$. Thus the derived amplitude scale height is about $27 \mathrm{~km}$. Since this scale height is larger than expected for a monochromatic freely propagating wave, we may conclude that the wavy structure was generated by several waves of different energy or that wave energy got lost during propagation to the mesosphere.

\subsection{Evolution of the wind throughout the measurement}

A vertical profile of zonal wind speed derived by RMR and $\mathrm{Na}$ lidar during one of the long measurements is shown in Fig. 9. The lidar data were integrated over $\approx 10 \mathrm{~h}$ during the night of 26/27 January (16:40-03:00 UT). In the height range of overlap (79-83 km), both lidar winds are shown and match very well (except for the top altitudes $82-83 \mathrm{~km}$ ), showing the same wind speed within the error bars. ECMWF wind data for 18:00 UT, 00:00 UT, and 06:00 UT indicate temporal variability.

In Fig. 10 we show the temporal evolution of wind speed measured by RMR lidar and Na lidar. In the height range of overlap (roughly $78-85 \mathrm{~km}$ ) and above, only wind derived

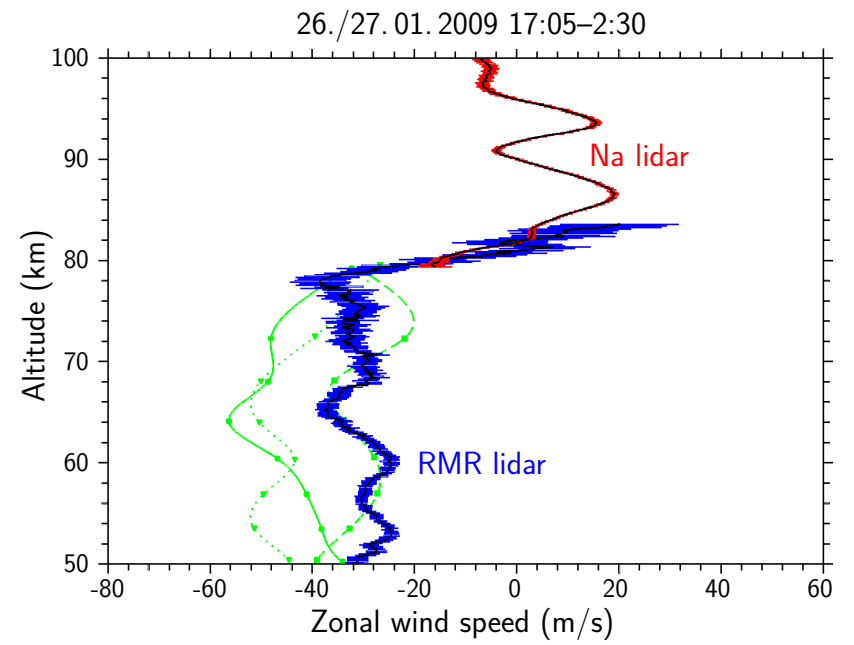

Fig. 9. Nightly mean vertical profiles of zonal wind speed on 26/27 January measured by RMR lidar (blue error bars) and Na lidar (red error bars) with the NWT. Integration time is roughly $10 \mathrm{~h}$. Green lines show zonal wind speed from ECMWF data (dashed: 18:00 UT, solid: midnight, dotted: 06:00 UT; dots mark the model levels). Note that, in the height range of overlap (79-83 km), winds derived by both lidars are shown and match very well (except for the top altitudes $82-83 \mathrm{~km}$ ).

by Na lidar is shown. The data are smoothed with a running mean filter with window size of $1 \mathrm{~h}$. The left panel shows the complete altitude range between 30 and $110 \mathrm{~km}$, the right panel a close-up between 65 and $85 \mathrm{~km}$ altitude, highlighting the transition from RMR lidar to Na lidar data at 77$79 \mathrm{~km}$ (indicated by black line). The transition is smooth most of the time, but there are some differences: around 18:30 UT, 20:00 UT, 00:00 UT, and 02:00 UT, both lidars yield different wind speeds at the transition altitude with difference of up to $20 \mathrm{~ms}^{-1}$. However, this transition altitude is at the signal range limit for both lidars. The measurement uncertainty in this altitude range is $\approx 15-20 \mathrm{~ms}^{-1}$ for the RMR and $\approx 5 \mathrm{~ms}^{-1}$ for the Na lidar data. Thus even these differences do not falsify the good agreement of RMR and $\mathrm{Na}$ lidar. Regarding the atmospheric conditions during this day, we find remarkable variations of the wind throughout the measurement. Above $90 \mathrm{~km}$ altitude we observe tidal signatures: strong westward wind around 22:00 UT and strong eastward wind previously and afterwards. Hourly mean winds between 95 and $105 \mathrm{~km}$ altitude are $(25 /-65 / 30) \mathrm{ms}^{-1}$ at 19:00/22:00/01:00 UT. Below $80 \mathrm{~km}$ the wind is mostly westward with wind speeds up to $-50 \mathrm{~ms}^{-1}$.

The vertical black lines in Fig. 10 indicate selected times for which vertical profiles integrated over $1 \mathrm{~h}$ are shown in Fig. 11. In these panels we include also wind speeds from ECMWF data (green lines). Both lidar wind speeds match well. Especially at 18:00 UT, both instruments yield similar wind speed (RMR: $(-23.4 \pm 16.8) \mathrm{ms}^{-1}$, Na: 

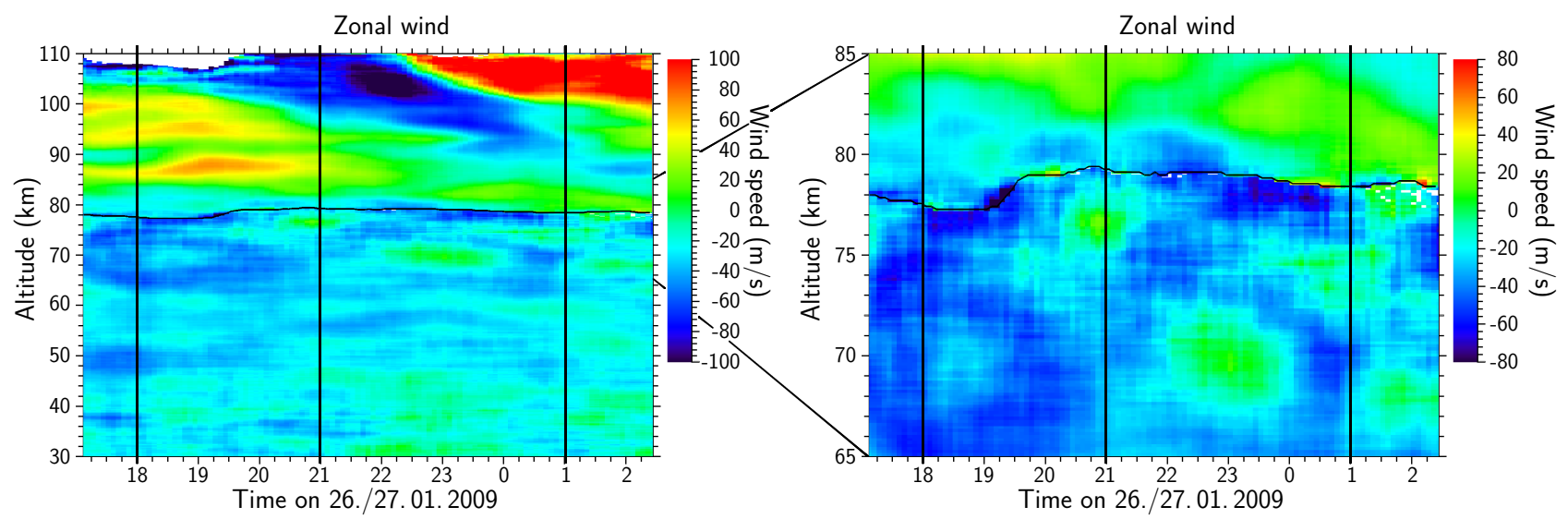

Fig. 10. Zonal wind speed on 26/27 January measured by RMR and Na lidar with the NWT. In the height range of overlap (roughly $78-$ $85 \mathrm{~km}$ ) and above, only wind from Na lidar is shown. Left panel: complete altitude range between 30 and $110 \mathrm{~km}$. Right panel: close-up between 65 and $85 \mathrm{~km}$ altitude, highlighting the transition from RMR lidar to Na lidar data at 77-79 km (indicated by black line). Vertical black lines indicate profiles of zonal wind speed shown in Fig. 11.

$\left.(-31.0 \pm 4.3) \mathrm{ms}^{-1}\right)$; at 21:00 UT there is a larger difference, but still the wind speed is similar within the error bars (RMR: $(-36.5 \pm 18.2) \mathrm{ms}^{-1}$, Na: $\left.(-19.8 \pm 4.8) \mathrm{ms}^{-1}\right)$; at 01:00 UT both profiles are identical for the first $200 \mathrm{~m}$, but differ at the topmost kilometer of the RMR data (RMR: $(15.3 \pm 18.2) \mathrm{ms}^{-1}$, Na: $\left.(5.8 \pm 5.1) \mathrm{ms}^{-1}\right)$. The ECMWF data for a specific time do not represent the actual wind speed sufficiently: at 18:00 UT and 01:00 UT the temporally closest ECMWF profile (solid) differs substantially from the lidar profiles. A similar behavior can also be seen in Fig. 9. That the deviations appear randomly could indicate that smallscale fluctuations in the ECMWF data are not in phase with the observations. Similar to the observation shown in Fig. 6a, where we see phase differences in altitude, we find phase differences in time. However, a statistical analysis is beyond the scope of this work.

\subsection{Continuous wave patterns in RMR and Na data between 60 and $110 \mathrm{~km}$ altitude}

During the longest coincident measurement in the night of 22/23 January, from 19:00 UT until 07:00 UT, the NWT pointed to north, probing south-north (meridional) wind. The resulting time-height section is shown in the left panel of Fig. 12. We show only wind observations with a measurement uncertainty of less than $20 \mathrm{~ms}^{-1}$ for the RMR data. Faint tropospheric clouds passed over the observatory, e.g. around 21:15 UT. This results in some discarded records and a reduced upper limit of the RMR lidar data $(\approx 84 \mathrm{~km})$. Compared to the observations on 26/27 January, the lower edge of the sodium layer was higher. Both factors result in a small overlapping altitude range, if any. Most of the time there is a narrow gap between RMR and Na lidar data. Although the data of the two lidar systems show little overlap during this day, we can use this dataset to show the correct

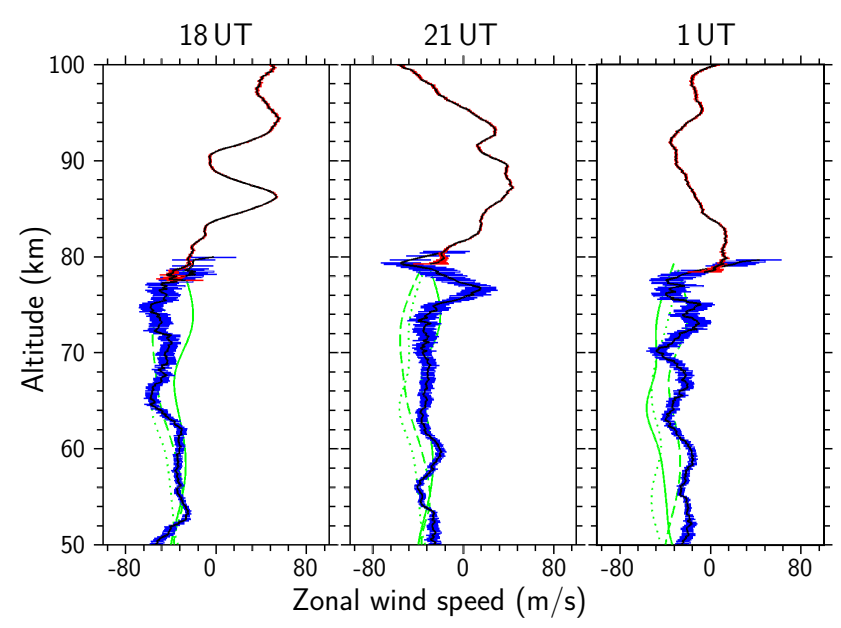

Fig. 11. Vertical profiles of zonal wind speed on 26/27 January measured by RMR lidar (blue error bars) and Na lidar (red error bars) with the NWT. Green lines show wind speed profiles from ECMWF data (solid: closest, dashed: $6 \mathrm{~h}$ earlier, dotted: $6 \mathrm{~h}$ later). Integration time for lidar data is $1 \mathrm{~h}$. Profiles are centered at 18:00 UT, 21:00 UT, and 01:00 UT.

retrieval, especially with regard to projection of the line-ofsight wind on the horizontal plane. The gap at 02:30 UT is caused by tilting the telescope to a different elevation angle: until 02:30 UT the NWT pointed to north $30^{\circ}$ off-zenith; thereafter the zenith distance angle was $20^{\circ}$. This results in a horizontal displacement of the sounding volume of 8.5 , 12.8 , and $17.1 \mathrm{~km}$ at altitudes of 40,60 , and $80 \mathrm{~km}$, respectively. There is no sudden change in meridional wind speed, indicating that the meridional wind is homogeneous over the mentioned distances, and the projection of line-of-sight wind on the horizontal plane is correct. The projection factor 

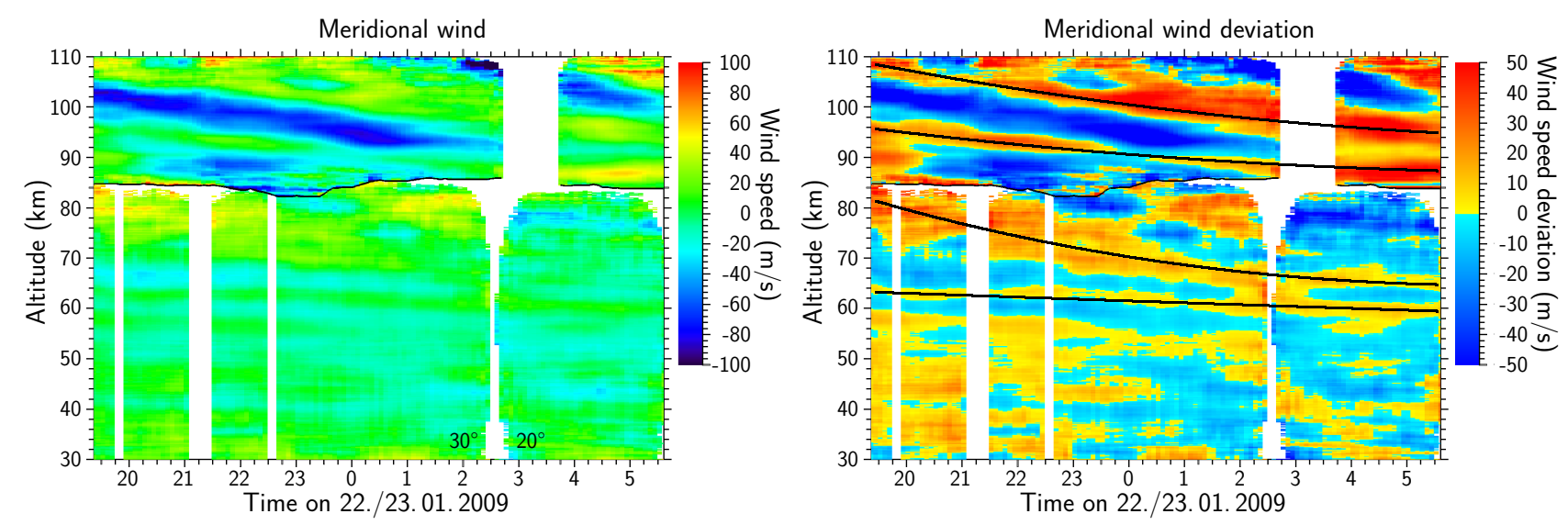

Fig. 12. Time-height section of absolute meridional wind speed (left panel) and its deviation from the mean wind speed profile (right) on 22/23 January measured by RMR and Na resonance lidar with the NWT. The elevation angle was changed at $02: 30$ UT from $30^{\circ}$ to $20^{\circ}$ off-zenith. Black lines in the right panel highlight maxima of wind deviation showing a wavelike structure with varying amplitudes, vertical wavelengths, and slope of the phases.

$p=v_{\text {LOS }} / v_{\text {horizontal }}$ changes from $p=2.0$ (for $30^{\circ}$ ) to $p \approx 2.9$ (for $20^{\circ}$ ).

Especially in the Na lidar data, but also in RMR lidar data, wavelike structures are obvious. To highlight this enhanced wave activity, we calculate wind speed deviation by subtracting the mean wind speed profile. The resulting time-height section is shown in the right panel of Fig. 12. The black lines highlight maxima of meridional wind speed. The amplitude of the wavelike structures increases with altitude. Vertical wavelength and slope of wave phase vary with time. The lowermost maximum (at around $60 \mathrm{~km}$ altitude) that can be observed continuously throughout the measurement has an amplitude of about $10 \mathrm{~ms}^{-1}$. This phase of a wavelike structure is nearly constant in altitude, descending only slightly from $63 \mathrm{~km}$ altitude at the beginning of the measurement to $60 \mathrm{~km} 9 \mathrm{~h}$ later. The maximum above starts at about $81 \mathrm{~km}$ and descends to $65 \mathrm{~km}$; its amplitude decreases from 30 to $10 \mathrm{~ms}^{-1}$. The upper two maxima show very similar behavior: they descend nearly parallel from $96 \mathrm{~km}(109 \mathrm{~km})$ down to $87 \mathrm{~km}(95 \mathrm{~km})$; their amplitude increases slightly from 30 to $40 \mathrm{~ms}^{-1}$. Downward phase progressions are typical for upward propagating gravity waves and tides (Chanin and Hauchecorne, 1981; Oberheide et al., 2002). A possible explanation for the decrease of vertical wavelength in the altitude range $60-85 \mathrm{~km}$ might be the observed decrease in meridional wind speed from $\approx 10 \mathrm{~ms}^{-1}$ around 20:00 UT to $\approx-5 \mathrm{~ms}^{-1}$ around 05:00 UT in that altitude range.

\section{Conclusions}

We performed for the first time simultaneous wind observations using two different lidar instruments with the same line of sight, covering the altitude range of about 30 to $110 \mathrm{~km}$, probing a common sounding volume between about 80 and
$85 \mathrm{~km}$ altitude. Compared to a previous study by Baumgarten (2010), we analyzed the data with a time resolution of $1 \mathrm{~h}$ only ( $2 \mathrm{~h}$ in the previous study), to investigate signatures of atmospheric gravity waves in the wind profiles throughout the middle atmosphere. For data of the RMR lidar, we applied different validation and calibration methods using either two beams of the same lidar or a single vertical pointing beam. In the latter case we identified instrumental effects (phase of RFS) that need to be taken into account when analyzing the data throughout a more extensive period as used in a previous study. When including these effects in the analysis, we find good agreement between RMR and Na lidar data as well as between the two beams of the RMR lidar. We identified signatures of a horizontally inhomogeneous wind field even in a wind profile averaged over a period of $4 \mathrm{~h}$. This highlights the importance of common volume observations when comparing wind profiles from two different instruments.

The combination of RMR and Na lidar allowed us to identify wave structures from the lower stratosphere to the mesopause. We found that in one case the amplitude scale height is about $27 \mathrm{~km}$, indicating that the wave loses energy or that the observed structures are generated by a composition of waves.

Another example shows that phases of a wavelike structure are clearly visible from $60 \mathrm{~km}$ to above $100 \mathrm{~km}$ altitude, where the vertical wavelength decreases with time, especially in the upper mesosphere.

We conclude that a successful and meaningful comparison of different measurement techniques requires simultaneous and common volume observations where the extent of the common volume is defined by the sizes of the sounding volumes of the instruments, and the sounding volumes must be of comparable size. For the applied integration time of $1 \mathrm{~h}$, this is fulfilled in our study: the sounding volumes of both 
lidars are on the order of tens of meters, separated by a few tens of meters.

Acknowledgements. The work benefited from the excellent support by the dedicated staff at the ALOMAR observatory and the voluntary lidar operator during this campaign Natalie Kaifler. The European Centre for Medium-Range Weather Forecasts (ECMWF) is gratefully acknowledged for providing the operational analysis data on 91 model levels. The DoRIS project is supported by DFG (Deutsche Forschungsgemeinschaft, BA 2834/1-1). The Na lidar observations were founded by the Research Council of Norway through grant 191755 and the US National Science Foundation through grants AGS-0545262, AGS-1042216, and AGS-1136269.

Edited by: A. Stoffelen

\section{References}

Alexander, M. J. and Barnet, C.: Using satellite observations to constrain parameterizations of gravity wave effects for global models, J. Atmos. Sci., 64, 1652-1665, doi:10.1175/JAS3897.1, 2007.

Baumgarten, G.: Doppler Rayleigh/Mie/Raman lidar for wind and temperature measurements in the middle atmosphere up to 80 km, Atmos. Meas. Tech., 3, 1509-1518, doi:10.5194/amt-31509-2010, 2010.

Chanin, M.-L. and Hauchecorne, A.: Lidar observation of gravity and tidal waves in the stratosphere and mesosphere, J. Geophys. Res., 86, 9715-9721, doi:10.1029/JC086iC10p09715, 1981.

Cot, C. and Barat, J.: Wave-Turbulence Interaction in the Stratosphere, J. Geophys. Res., 91, 2749-2756, 1986.

Fiedler, J., Baumgarten, G., and von Cossart, G.: A middle atmosphere lidar for multi-parameter measurements at a remote site, in: Reviewed and revised papers presented at the 24th International Laser Radar Conference, 23-27 June 2008, Boulder, Colorado, USA, 824-827, 2008.

Friedman, J. S., Tepley, C. A., Castleberg, P. A., and Roe, H.: Middle-atmospheric Doppler lidar using an iodine-vapor edge filter, Opt. Lett., 22, 1648-1650, 1997.

Fritts, D. C. and Alexander, M. J.: Gravity wave dynamics and effects in the middle atmosphere, Rev. Geophys., 41, 1003, doi:10.1029/2001RG000106, 2003.

Goldberg, R. A., Fritts, D. C., Schmidlin, F. J., Williams, B. P., Croskey, C. L., Mitchell, J. D., Friedrich, M., Russell III, J. M., Blum, U., and Fricke, K. H.: The MaCWAVE program to study gravity wave influences on the polar mesosphere, Ann. Geophys., 24, 1159-1173, doi:10.5194/angeo-24-1159-2006, 2006.

Hauchecorne, A. and Chanin, M.-L.: Density and temperature profiles obtained by lidar between 35 and $70 \mathrm{~km}$, Geophys. Res. Lett., 7, 565-568, doi:10.1029/GL007i008p00565, 1980.

Hoppe, U.-P. and Fritts, D. C.: High-resolution measurements of vertical velocity with the European incoherent scatter VHF radar: 1. Motion field characteristics and measurement biases, J. Geophys. Res., 100, 16813-16825, doi:10.1029/95JD01466, 1995.
Huang, W., Chu, X., Williams, B. P., Harrell, S. D., Wiig, J., and She, C.-Y.: Na double-edge magneto-optic filter for Na lidar profiling of wind and temperature in the lower atmosphere, Opt. Lett., 34, 199-201, doi:10.1364/OL.34.000199, 2009.

Junge, C. E., Chagnon, C. W., and Manson, J. E.: Stratospheric aerosols, J. Meteorol., 18, 81-108, doi:10.1175/15200469(1961)018<0081:SA > 2.0.CO;2, 1961.

Kaifler, B.: Na Lidar at ALOMAR - electronic improvements, analysis algorithms, and selected atmospheric observations 80 to $100 \mathrm{~km}$ above Northern Norway, Master's thesis, University of Ulm, Ulm, Germany, 2009.

Kent, G. S. and Wright, R. W. H.: A review of laser radar measurements of atmospheric properties, J. Atmos. Terr. Phys., 32, 917-943, 1970.

Liu, A. Z., Hocking, W. K., Franke, S. J., and Thayaparan, T.: Comparison of $\mathrm{Na}$ lidar and meteor radar wind measurements at Starfire Optical Range, NM, USA, J. Atmos. Sol.-Terr. Phys., 64, 31-40, doi:10.1016/S1364-6826(01)00095-5, 2002.

Müllemann, A. and Lübken, F.-J.: Horizontal winds in the mesosphere at high latitudes, Adv. Space Res., 35, 1890-1894, 2005.

Oberheide, J., Hagan, M. E., Roble, R. G., and Offermann, D.: Sources of nonmigrating tides in the tropical middle atmosphere, J. Geophys. Res., 107, 4567, doi:10.1029/2002JD002220, 2002.

She, C. Y., Vance, J. D., Williams, B. P., Krueger, D. A., Moosmuller, H., Gibson-Wilde, D., and Fritts, D.: Lidar studies of atmospheric dynamics near polar mesopause, Trans. Am. Geophys. Union (EOS), 83, 289-293, doi:10.1029/2002EO000206, 2002.

Singer, W., Keuer, D., and Eriksen, W.: The ALOMAR MF radar: Technical design and first results, in: Proceedings 13th ESA Symposium on European Rocket and Balloon Programmes and Related Research, Oeland, Sweden, 26-29 May 1997, edited by: Kaldeich-Schürmann, B., vol. ESA SP-397, 101-104, 1997.

Singer, W., Bremer, J., Hocking, W. K., Weiss, J., Latteck, R., and Zecha, M.: Temperature and wind tides around the summer mesopause at middle and Arctic latitudes, Adv. Space Res., 31, 2055-2060, doi:10.1016/S0273-1177(03)00228-X, 2003.

Souprayen, C., Garnier, A., Hertzog, A., Hauchecorne, A., and Porteneuve, J.: Rayleigh-Mie Doppler wind lidar for atmospheric measurements, I. Instrumental setup, validation, and first climatological results, Appl. Optics, 38, 2410-2421, doi:10.1364/AO.38.002410, 1999.

Tepley, C. A.: Neutral winds of the middle atmosphere observed at Arecibo using a Doppler Rayleigh lidar, J. Geophys. Res., 99, 25781-25790, doi:10.1029/94JD02213, 1994.

von Zahn, U., von Cossart, G., Fiedler, J., Fricke, K. H., Nelke, G., Baumgarten, G., Rees, D., Hauchecorne, A., and Adolfsen, K.: The ALOMAR Rayleigh/Mie/Raman lidar: objectives, configuration, and performance, Ann. Geophys., 18, 815-833, doi:10.1007/s00585-000-0815-2, 2000.

Widdel, H.-U.: Foil chaff clouds as a tool for in-situ measurements of atmospheric motions in the middle atmosphere: Their flight behaviour and implications for radar tracking, J. Atmos. Terr. Phys., 52, 89-101, doi:10.1016/0021-9169(90)90071-T, 1990. 
Williams, B. P., Fritts, D. C., Wang, L., She, C.-Y., Vance, J. D., Schmidlin, F. J., Goldberg, R. A., Müllemann, A., and Lübken, F.-J.: Gravity waves in the arctic mesosphere during the MaCWAVE/MIDAS summer rocket program, Geophys. Res. Lett., 31, L24S05, doi:10.1029/2004GL020049, 2004.

Xia, H., Dou, X., Sun, D., Shu, Z., Xue, X., Han, Y., Hu, D., Han, Y., and Cheng, T.: Mid-altitude wind measurements with mobile Rayleigh Doppler lidar incorporating system-level optical frequency control method, Opt. Express, 20, 15286-15300, doi:10.1364/OE.20.015286, 2012.
Yue, J., She, C.-Y., Williams, B. P., Vance, J. D., Acott, P. E., and Kawahara, T. D.: Continuous-wave sodium D2 resonance radiation generated in single-pass sum-frequency generation with periodically poled lithium niobate, Opt. Lett., 34, 1093-1095, doi:10.1364/OL.34.001093, 2009. 